\title{
Artificial Neural Networks and its Role in Plant Breeding Under Drought Stress
}

\author{
Mohammad Reza Naroui Rad* \\ Horticultural and Crop Research Department, Sistan Agriculture and Natural Resources Research Center, AREEO, Zabol, Iran
}

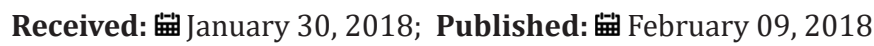

*Corresponding author: Mohammad Reza Naroui Rad, Horticultural and Crop Research Department, Sis tan Agriculture and Natural Resources Research Center, Iran

\section{Introduction}

All plants need water for the process of photosynthesis to take place effectively. Lack of enough water in plants decreases stomata conductivity that limits the uptake of carbon dioxide which is a necessary element for photosynthesis. The best way of increasing yield and subsequent profit is by performing early detections and managing the problems relating to crop yield. It is, therefore, important to develop models to evaluate crop production behavior specifically weather as it helps in minimizing costs incurred through operation and analysis and evaluate stability In stimulating the egg plant relative water content's response to condition of weather of sis tan, two models; Multilayer Perception (MLP) and Artificial Neural Network (ANN) together with some input variables such as; the height of a plant, weight of a fruit, length of a fruit, widths of a fruit, number of fruits, fruit lengths ratio to its width, chlorophyll, total yield and canopy temperature were developed. According to the results obtained from the ANN model, it was found that the ANN Model was the best. This is because the results obtained from; training, testing phase's precision and validating had a very low absolute error of $0.035,0.033$ and 0.027 respectively for MLP 9-151in egg plant. The highest correlation coefficient characteristics were the selected network at the concurrently low amplitude among the sets: validation, training, and the test one $0.83,0.86$ and 0.83 respectively.

In conditions of insufficient water that is during dry seasons, physiological and morphological responses shows that it leads to; a reduction in the fruit yield, plant vegetative development, quality, increase in stomata resistance and photosynthetic activity decreases [1]. Morphological and physiological responses under limited water conditions in dry weather condition, results commonly showed reduction in fruit yield, quality, plant vegetative development and increase in stomata resistance, decrease in photosynthetic activity [2-4]. Egg plant can present various shapes, colors and sizes given that it is a tropical fruit. However, this depends on the weather of cultivator, where it growth in [5]. Excessive soil moisture and deficiency gross effects on plant growth are known with drainage and irrigation. However, the farmer has higher chances of exercising control over the soil moisture than he or she can do with the other physical characteristics of the soil. This is a lively controversy which has been existing for several years concerning whether the available moisture is really equally available for growth of a plant or only available with the difficulties found in growth of a plant in that they are retarded even before they reach the wilting period. All these points of view have been summarized by [6] in their article reviews. Stress resistance crop genetic improvement needs investigation of probable physiological and Genetic improvement of crops for stress resistance requires investigation of probable physiological and results to attributes together with their genetic variation exploitation [7].

Full understanding the complex biophysical, biochemical, and biochemical molecular foundations of plants stress tolerance is only the important theoretical problem in environmental science and in ecology and in finding solutions for the problems of agriculture and increasing the yield of crops, there are some practical applications that can be used [8]. RWC is articulated as a proportion of the highest content of water that a tissue of a plant is able to retain [9]. RWC is, therefore, perceived as the best criterion status of plant water [10]. For regions with low water that could be gained, some physiological parameters like RWC are useful to know the performance of crop according to weather changes like drought. ANNs are taken to be among the most precise, efficient and extensively applied techniques for mining data and predicting it. According to previous studies, it has been proved that a network is able to make estimations of any function to the precision anticipated level [11]. According to ANNs work, depending on the direct relationship of various elements which are able to determine 
the connection between entrance and exit signals according to the patterns provided. Such elements are considered as neurons of the ANNs. The main advantage with this method is that it supports simple simulations and also it does not require any kind of analytical formulation. Various researchers have applied this technique in several aspects of cultivation and yield management specifically for predicting the total yield and model was found to be more accurate [12]. The main aim of conducting this study is to determine a method to apply the ANNs model to forecast RWC according to some physiological and morphological parameters in an eggplant under Sis tan weather condition. Selection of the optimum MLP 9-15-1 network was made based on the network that was trained with the error back propagation method for 520 epochs and using the conjugate gradients for 475 epochs, and again back propagation method for 237 epochs. The relative lowest absolute error characteristics and the highest correlation coefficient at the lowest amplitude between the sets; validation, training and test one were selected, the artificial neural network (ANN) developed model was subjected to compare the observations using the predicated values.

According to the Artificial Neural Network results, it was revealed that the neural network models had good performance in validating, training and testing phase's precision with a low average absolute error of $0.027,0.035$ and 0.033 respectively for MLP 9-15-1. The highest correlation coefficient characteristics at the simultaneously low amplitude in the sets; validation, training and the test one $0.86,0.83$ and 0.86 was the network selected. In predicting the Retained Water Content, a worked out model should be used but only under Sis tan weather condition. In addition, it is important to increases the training set for more investigation. Artificial Neurons Network have been applied for purposes of modeling in various fields like; hydrology, agro-ecology and metrological research. In estimating monthly evapo transpiration, ANNs have also been more useful. ANNs have also been used to estimate monthly evapo transpiration (ET) [13]. Different statistical methods and multivariate analysis have been used in evaluating and modeling plant growth and developments, including simple correlation, multivariate regression, path analysis and principal component analysis, but some of them have been used to model the relationship between yield stability and physiological traits related to plant water status [14]. It has been reported in several studies concerning the application of predictive models for influent of water characteristics $[15,16]$. Naroui Rad $[17,18]$ implemented ANN for selection of best traits to increase fruit yield in melon.

\section{References}

1. Sevinc B, Sekure SE (2013) Effect of genotypical factors on the effectiveness of another culture in eggplant (Solanum melongena L.). Turk J Biol 37(4): 499-505.
2. Paksoy M, Akilli M (1994) The effects of different prunings on the yield and quality of egg plant cultivars grown in the greenhouse conditions. Acta Hort 366: 287-292.

3. Esiyok D, Eser B (1998) The effect of stem pruning on yield and earliness of greenhouse eggplants. Sebze tarimi semp Proc 2: 130-134.

4. Czarnowski M (1995) Photosynthesis in green pepper fruits. Folia Hort $7(1): 37-47$

5. Bala B, Ashraf M, Uddin M, Janjai S (2005) Experimental and neural network prediction of the performance of a solar tunnel drier for a solar drying jack fruit bulbs and leather. J Food Proc Eng 28(6): 552-566.

6. Timberlake CF (1981) Anthocyanins in fruit and vegetables. In J Friend, MJC Rhodes (Eds) 221-247.

7. Veihmeyer FJ, Hendrickson AH (1950) Essentials of irrigation and cultivation of orchards. Univ of Calif Agr Ext Service Circ 50: 23.

8. Brancourt Hulmel M, Doussinault G, Lecomte C, Berard P, Le Buanec B, et al. (2003) improvement of agronomic traits of winter wheat cultivars released in France from 1946 to 1992. Crop Sci 43: 37-45.

9. Kreslavski V, Tatarinzev N, Shabnova N, Semenova G, Kosobryukhov A (2008) Characterization of the nature of photosynthetic recovery of wheat seedlings from short term dark heat exposures and analysis of the mode of acclimation to different light intensities. J Plant Physiol 165(15): 1592-1600.

10. Grace J, MJ Crawley (1997) Plant Water Relations (Ed.) Blackwell. Plant Ecology 28-50.

11. Hassanzadeh M, Ebadi A, Panahyan e Kivi A, Eshghi AG, Jamaati e Somarin $S$, et al. (2009) Evaluation of drought stress on relative water content and chlorophyll content of sesame (Sesamum indicum L.) genotypes at early flowering stage. Res J Environ Sci 3(3): 345-350.

12. Solaimany Aminabad M, Maleki A, Mahdi H (2013) Application of artificial neural network (ANN) for the prediction of water treatment plant influent characteristics. J Adv Environ Health Res 1(2): 1-12.

13.Zhang H, Hu H, Zhang X, Zhu L, Zheng K, et al. (2011) Estimation of rice neck blasts severity using spectral reflectance based on BP neural network. Acta Physiologiae Plantarum 33(6): 2461-2466.

14. Khoob AR (2008) Comparative study of Hargreaves's and artificial neural network's methodologies in estimating reference evapotranspiration in a semiarid environment. Irrigation Sci 26 (3): 253-259.

15. Dong B, Liu M, Shao HB, Li Q, Shi L, et al. (2008) Investigation on the relationship between leaf water use efficiency and physio biochemical traits of winter wheat under rained condition. Bio 62 (2): 280-287.

16. Pai TY, Tsai YP, Lo HM, Tsai C, Lin C (2007) Grey and neural network prediction of suspended solids and chemical oxygen demand in hospital water treatment plant effluent. Computers \& Chemical 31 (10): 12721281.

17. El Din A, Smith D (2002) A neural network model to predict the waste water inflow incorporating rainfall events. Water Res 36(5): 1115-1126.

18. Naroui Rad MR, Koohkan SH, Fanaei HR, Pahalavan Rad MR (2015) Application of Artificial Neural Networks to predict the final fruit weight and random forest to select important variables in native population of melon (Cucumis melo L). 181(2): 108-112. 
This work is licensed under Creative Commons Attribution 4.0 License To Submit Your Article Click Here: Submit Article

DOI: 10.32474/CIACR.2018.01.000106

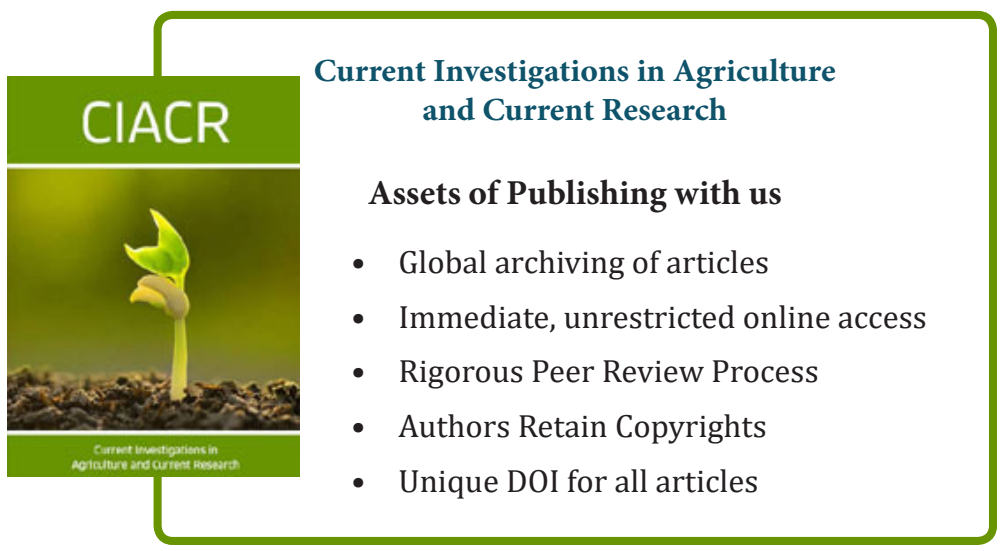

